\title{
RAYUELA: LA CUESTIÓN DEL NARRADOR
}

\author{
Adriana Bocchino \\ Universidai Nacional de Mar Del Plata
}

LE LOCUTEUR dans le roman est, toujours, a đivers degrẻs, un idéologue, et ses paroles sont toujours un idéologème...

Mikhail Baktine: Esthétique et thêorie du roman

\begin{abstract}
RESUMO
Indaga-se neste artigo a funcionalidade do narrador no conhecido romance de Julio Cortázar. Observa-se um contínuo desdobramento do narrador básico ou sujeito da enunciação segundo très quesitos: 1. Outros escritores reais, 2. escritores ficcionais e 3. personagens-narradores. Assim, falamos de um sujeito da enunciação que simulta. neamente se configura como actante cuja açāo é a de contar uma experiência de criação na qual se inspira a anedota e o leitor. Narrador e leitor se inscrevem no fato transgressivo que significa escrever Rayuela como romance que não é e deixar-se ler somente interpretando-o desde si mesmo.
\end{abstract}

La problemática que nos ocupa en el siguiente trabajo parte de la pregunta acerca del esclarecimiento y funcionalidad del narrador de Rayuela. ${ }^{1}$ Desde qué instancia se cumple la cuestión de la ambiguiedad que lleva a la multiplicidad percebida inmediatamente en la lectura de la novela?

Margary A. Safir ha estudiado los efectos de la conducta transgresiva como un comportamiento extremo en el nivel de los personajes." Nuestro propósito es el de alcanzar una

1 Cortazar, J. Rayuela, 12. ed. Bueros Aires, Sudamerlcana, 1970, Las cltas da Rayuela se realizan de esta edicion. que sigue la primera edicion de la misma casa.

2 Margary SAFIR: Para un erotismo do la llberacion; notas sobre el comportamiento transgresivo en 'Rayuela' y 'E] Llbro de Manuel' en La isla final, recop. de J.Alazrekt $\mathrm{Y}$ otros. Navarra. UItramar. 1983. 
explicación acerca de la conducta transgresiva del Narrador en sí mismo. Consideramos que el modelo de comportamiento extremo del narrador actúa, como en el caso de los personajes, operando una suerte de liberación.

En principio cabe preguntarse por el narrador de Rayuela: si es uno, sin son varios y si hay desdoblamientos, o que tipo de recursos utiliza en su manifestación sin olvidar las dos posibilidades de lectura que se presentan.

Los acontecimientos, tanto en la lectura lineal como la que incluye los capitulos prescindibles son ordenados por un narrador básico o supranarrador, según tres partes que hacen referencia a tres espacios ("el lado de allá", "el lado de acá" y de otros lados"), introducidas por dos epígrafes generales (el del Abad Martini y el de César Bruto) y dos epigrafes especificos a cada una de las dos primeras partes (el de Jacques Vaché y el de Apollinaire) con un claro valor paródico. ${ }^{3}$ El narrador que denominamos básico organiza los materiales del texto $\mathrm{y}$ es identificable, desde la ficción misma, con el novelista: el "Tablero de dirección" presenta ya un narrador, pero no hallamos un personaje al cual se refiera el punto de vista; es el narrador mismo quien se constituye como actante del discurso. En el tablera se inicia la ficción narrativa a partir de la cual irrumpe un tipo de narrador particular y poco usual dentro de los términos tradicionales del género novela.

En los capítulos correspondientes al nivel de las acciones predomina la posición de un narrador en tercera persona referida al punto de vista del personaje Horacio Oliveira. Se trataría de una visión desde el personaje, en la cual el Narrador básico, sin embargo, toma una distancia reflexiva.

La narración puede manifestarse también en primera persona del singular o del plural, pero aun en el plural el narrador que organiza los datos lo hace desde la perspectiva de Oliveira, así como los diálogos en los que el mismo personaje interviene. ${ }^{*}$ Sin embargo debemos hablar de una visión alterna (y no univoca) puesto que los otros personages pueden ocasionalmente ser el foco de referencia para el punto de vista del narrador básico asumiendo sus propios discur-

3 Para aclarar el concepto de parodia vésae el artículo de Bevero BARDUY. El barroco y el neobarroco. In: AMERICA Latina en su literatura. Merlco. Blalo XXI, 1972. p. 174 $\mathrm{y}$ ss. Tamblén de Fernando AINBA. Las dos orlllas le Jullo Cortazar. Revista Iberoamericana, 84/85: 425-56. Jul./dic. 1073.

1 La diatanclación del Narrador báalco se marca por la utillzacion de la tercera persons $y$ cl encomillsdo de clertos discursos que en sf no se diferenclam estilfstics. mente de los otros salro por la utilizacion de la persons gramatlcal. El discurso encomlliado responde al fluir de consclencla de clertos personajes. poro sobre todo de Horaclo Olivetra. 
sos. ${ }^{5}$ El narrador básico salta de una visión a otra sin especificar claramente los cambios sino sólo a través de marcas de estilo o referencias circunstanciales.

Por ejemplo, desde el capítulo 1 a 21 registra, en el nivel de las acciones, sólo un hombre que piensa y camina, Horacio Oliveira; sin embargo la inserción de diversos personajesnarradores en el raconto base hace posible que las visiones se superpongan.

A partir del capítulo 22 el Narrador varía su técnica: las diversas visiones se hacen cada vez más independientes, fluctúan de acuerdo a los personajes. Sobre todo se hace notable en la segunda parte, en la cual Talita y Traveler cobran un nivel semejante al de Horacio y la Maga.

La forma dialogada predomina a partir del capitulo 22 y se hace cada vez más importante en la segunda parte. En este sentido el narrador básico ya no sigue un punto de vista fijo sino claramente alterno. Con simultaneidad su apartamiento de la visión desde Oliveira provoca un repliegue funcional del personaje principal. La forma dialogada pasa a ser la forma de presentación directa de los personajes en tanto se advierte una ausencia verbal reflexiva de Horacio Oliveira. Puede decirse que ocurre lo mismo a nivel del narrador: ya no hay introspección precisa, es irónico, no analiza como en la primera parte. Se ha dejado lugar, directamente, a los diversos locutores en que se han transformado los personajes, la multiplicidad del narrador se ve dispersada en los personajes y apunta a una relativización cada vez mayor. Se producen refracciones de sentido, de una vez a otra, de un discurso a dos o más voces. En tal sentido el plano simbólico que se observa respecto de los dobles y especialmente remitido a los personajes ${ }^{i}$ cabria relacionarlo y afincarlo en la problemática del narrador. Sobre la estructura de un narrador básico podemos hablar de los siguientes dobles:

5 En el capitulo 11, por ejemplo, Orenorovius sc manifiesta como otra forma del narrador básteo, puesta que una primera es la de Horaclo. En tal sentido Horaclo se constituye como el primero desdoblamento del narrador básico, en tanto Grecorovius como el secundo de esto $y$ primero de Olivelra. En cuanto a la Maca cabe aclararse que su presentación se hace desde la palabra pronunciada adoptando, directamente. la roz del narrador (cap. 15, por ejemplo).

- La carta de la Maga del capitulo 32 marca el Injcto discursivo de rediecue de de Horaclo Olivelra. Su tluir de conclencla deja de scr explleito y el Narrador opta por una presentación de personajes absolutamente tradicional. a tal punto que no deja de parecer parólico.

7 Ans Maris BARRENECHEA. Los dobles en el proceso de cscritura de Raguela. Revista tberica, 125;809-28, oct./dlc. 1983. 
1) Narrador identificable con el mismo rol del narrador-novelista: citas de autores reconocibles.

2) Narradores identificables con su mismo rol pero en el nivel ficcional: citas de autores inventados (Morelli, C. Piriz, el licenciado Cuevas, etc.).

3) Narradores insertos en la ficcionalidad pura: personajes-narradores (Morelli, Oliveira, la Maga, Talita, Traveler, etc.).

Por un lado, este Narrador básico, como ser que organiza el material de la novela es identificable con el sujeto de la enunciación, pero por otro, y con una funcionalidad superpuesta y coincidente a la anterior, se configura como actante. La acción novelistica de este narrador es la de contar (por escrito) hechos, lecturas, reflexiones, interpretaciones, apoyándose en citas textuales, citas imaginarias, en puntos de vista diversos, en personas gramaticales también diversas, en visiones superpuestas, cuyo objetivo es el de narrar una experiencia de creación que llegue al lector más o menos en los mismos términos en los que se produce su gestación y proceso.

El desdoblamiento del narrador básico patentiza el concepto de plurivalencia que se registra en todos los niveles de la novela: personajes, símbolos, mezcla de tonos, citas, el jazz, etc. El juego especular que lleva a cabo el Narrador, en primer lugar, se redistribuye en toda la novela, incluso puede marcarse en la estructura que separa una lectura lineal y otra ordenada por el tablero de dirección.

En la organización de los capítulos "De otros lados" es el Narrador, sujeto de la enunciación, quien propone un orden explícito desde el tablero de dirección.

Desde el punto de vista del narrador básico la novela se inicia en el capítulo 73 y se articula así una organización del relato donde el sujeto de la enunciación intercala en el hilo argumental de las dos primeras partes otros datos a partir de las interpretaciones del libro de Morelli o de otros libros, o de citas textuales asi también como posibilidades o variantes de escenas de la narración básico o reflexiones sobre ésta o insertando historias correlativas a la misma que la amplían.

El narrador de los capítulos prescindibles puede confundirse con el de las reflexiones de Horacio Oliveira o aun con las del mismo Morelli. Se advierte un borramiento del 
Narrador básico y se refuerza una posible indiferenciación que hace que el estatuto ficcional del Narrador básico se subsuma de manera natural en las personalidades de Horacio Oliveira y Morelli.

Entre los capítulos prescindibles se tiene, entonces, un Narrador, sujeto de la enunciación, que organiza las citas o el orden de los capitulos desde el tablero, pero otro que hace la cita Morelli - narrador. Cap. 136), el que a su vez es recordado o citado por otros personajes (Horacio y los demás), los que a su vez realizan interpretaciones colectivas (cap. 15 por ejemplo) o "recuerdan" hechos que no ocurrieron en el hilo argumental básico que responde al primer narrador.

Sin duda, los capitulos prescindibles son la más clara exposición de la conducta transgresiva del Narrador.

\section{... "Parecía proponer"... "un camino que} empezara a partir de la liquidación externa e interna. Pero había quedado casi sin palabras, sin gente, sin cosas y potencialmente, claro, sin lectores". . Rayuela, cap. 124, Págs. 559.

Este proceso de empobrecimiento y vaciamiento se extiende no sólo a Morelli, sino también a los personajes, y, sobre todo, al Narrador básico. Sucede, sin embargo, que este Narrador se separa del processo porque no se encuentra inmerso en él. Es parte actante, pero no de la historia, sino del discurso. El sujeto de la enunciación aparece como el Narrador de una experiencia de creación, un modelo de Narrador preocupado, explicitamente, por manifestar su comprensión de la novela como narración de un texto de creación literaria, ${ }^{\circledR}$ en donde la historia de Horacio y la Maga, como la de Talita y Traveler, queda subsumida.

El narrador básico quiere ser, en definitiva, el único personaje, desdoblado en múltiples personajes-narradores los que a su vez pueden ser también desdoblados por otros personajes.

En el juego de dobles que provoca el narrador no queda fuera el rol del lector: homologado a los lectores del libro de Morelli, los cuales se perfilan como dobles del narrador básico, seguin se ha visto, encuentra sus propios dobles en la novela."

8 Súmese a ello la publicación del Cuaderno de Biticora da Rayuela por cl cual se hace maniflesto que la problemática de proceso de creación es uns preocupación explicita.

- “...Para que sirve un escritor sino para destruir la literatura? $y$ nosotros. que no qucremos ser leclores-hembra para qué servimos sino para arudar en to postble a esa destrucción? (D. 503). 
La coincidencia de la conducta transgresiva se cumple desde el narrador-sujeto de la enunciación y desde el lectorsujeto de la recepción por un proceso contínuo de refracción.

El narrador-novelista se halla embarcado en una búsqueda basada esencialmente en un concepto de instauración de otra realidad que ayude al lector como a sí mismo a moverse en otras direcciones." El texto se propone como el lugar, el punto de partida pero también de llegada, de la ruptura recuperable. La transgresión se lleva a cabo principalmente a partir del Narrador que se explicita frente a un modelo específico de lector.

La actitud de objetivación del Narrador básico sobre los personajes se prolonga en sus dobles (personajes-narradores $)^{11}$ respecto de los otros personajes y los hechos. Al mismo tiempo el lector se ve homologado al grupo de lectores del libro de Morelli los que se constituyen como dobles del Narrador básico y objetivizan el texto a partir de la reflexión interpretativa. Narrador y Lector, por un movimiento de refracción y visión especular se encuentran inmersos en el hecho transgresivo que significa escribir Rayuela y leerla interpretándola. La otra dimensión, la otra realidad, el otro orden, es el objetivo del hecho transgresivo y el medio de la transgresión la palabra misma, el proceso de escritura así como el de lectura. Una forma de liberación, propuesta por el narrador básico, la constituye, precisamente, la lectura "De otros lados", por la cual se adviene a la noción no habitual de la novela.

\section{REFERENCIAS BIBLIOGRAFICAS}

1 AINSA, F. Las dos orillas de Julio Cortázar. Revista Iberica, 84/85: 425-56, jul./dic. 1973.

2 ALAZRAKI, J, et alii. La isla final. Navarra, Ultramar, 1983.

3 AMERICA Latina en su literatura. México, Siglo XXI, 1972.

4 BARRENECHA, A. M. Los dobles en el proceso de escritura de Rayuela. Revista Iberoamericana, 125:809-28, oct./dic. 1983.

5 CORTazar, J. Rayuela. 12.ed. Buenos Aires, Sudamericana, 1970.

10 El tema del lector merece un tratamiento espectfico asf como el concepto de "ja otra reaildad" en Rayuela.

11 Fil narrador básico aparece distanclado de sus personajes al mismo tlempo que los di-construyc. En el caso de los personajes esta acclón concreta se daria en Horacio iniranda las fotos qu rectstran cl proceso de una tortura. 